Int. J. Morphol.,

32(4):1190-1193, 2014

\title{
¿Apófisis o Proceso? Un Aporte Lógico a la Construcción de la Terminología Anatomía
}

\author{
¿Apophyses or Process? A Logical Contribution to the Construction of Anatomical Terminology
}

\author{
Jorge Eduardo Duque Parra,*** \& John Barco Ríos ${ }^{* * *}$
}

DUQUE, P. J. E. \& BARCO, R. J. ¿Apófisis o proceso? un aporte lógico a la construcción de la terminología anatomía. Int. J. Morphol., 32(4):1190-1193, 2014.

RESUMEN: En el presente trabajo se pretende cuestionar la inclusión en la Terminología Anatómica Internacional de dos términos con orígenes distintos para designar a una misma estructura. Bajo los preceptos de la Federación Internacional de Anatomistas (IFA), se estableció un listado de términos anatómicos en latín con el fin de facilitar la comunicación científica; sin embargo, en dicho listado aparecen algunos términos de origen griego que contradicen el precepto inicial. El término apófisis es de origen griego y su significado es ambiguo e impreciso, pues se presta a distintas interpretaciones, algunas veces erróneas, cuando se aplica para designar algunas salientes óseas. En contraposición, el término proceso, que se origina del latín processus, ofrece un significado más preciso y menos confuso, el cual se puede aplicar para designar a todas las salientes óseas. Puesto que el término vigente en la actual Terminologia Anatomica Internacional es el de proceso para designar a las prolongaciones óseas, se propone eliminar de dicha Terminologia Antomica el término apófisis, por ser menos preciso y de origen griego.

PALABRAS CLAVE: Apófisis; Anatomía; Osteología; Proceso; Terminología.

\section{INTRODUCCIÓN}

"No sólo debemos explicar ni sólo comprender; debemos concebir, y esto se hace mediante conceptos". Victor von Weizsaacker.

"Los palos pueden quebrantarme el cuerpo, pero los nombres no pueden dañarme" (Rich Harris, 1999). Esta aseveración popular desconoce que el cerebro integra la información corporal y de si mismo en una actividad cerebral. Por lo tanto, dicha aseveración no es considerada certeza, pues los nombres pueden herir terriblemente (Rich Harris) al influir sobre la actividad cerebral, que es la que reconoce el mundo exterior y, de éste, el lenguaje escrito en el que se incluye la terminología anatómica.

El lenguaje contribuye al avance de la ciencia (Duque-Parra et al., 2006), pero ¿es el uso del lenguaje general el mejor criterio para designar objetos en ciencia (DuqueParra et al., 2002) como sucede en el caso de las salientes que presentan los huesos en el campo de la Morfología? (Fig. 1). No necesariamente, pues existe un lenguaje común y otro científico, siendo éste último la fórmula utilizada para tratar de optimizar la comunicación entre las comunidades científicas y hacerla menos subjetiva para que tal comunicación sea más eficaz. Este vocabulario científico debe usarse con precisión para que tienda a ser infalible.

No obstante, algunos términos científicos pueden caer en desuso debido a su escasa o nula descripción del objeto estudiado, lo cual, en el caso morfológico, es determinado por la Federación Internacional de Anatomistas (IFA) que aglomera anatomistas de distintas nacionalidades, algo semejante a lo que se hace en la actualidad en los Simposios Ibero-latinoamericanos de Terminología (SILAT) organizados por la Asociación Panamericana de Anatomía (APA) (Losardo et al., 2010), que se realizan periódicamente desde el 2009 y que tienen como objetivo lograr una mejor precisión y claridad en la denominación de las diversas estructuras del cuerpo humano. Con el propósito de hacer más sencilla la comunicación entre los usuarios del lenguaje anatómico se estableció un listado de términos en latín, el cual

\footnotetext{
* Programa de Medicina, Departamento de Ciencias Básicas, Universidad de Caldas. Manizales.

** Departamento de Biología. Universidad Autónoma, Manizales, Colombia.

**** Programa de Medicina, Programa de Enfermería, Departamento de Ciencias Básicas, Universidad de Caldas, Manizales, Colombia.
} 


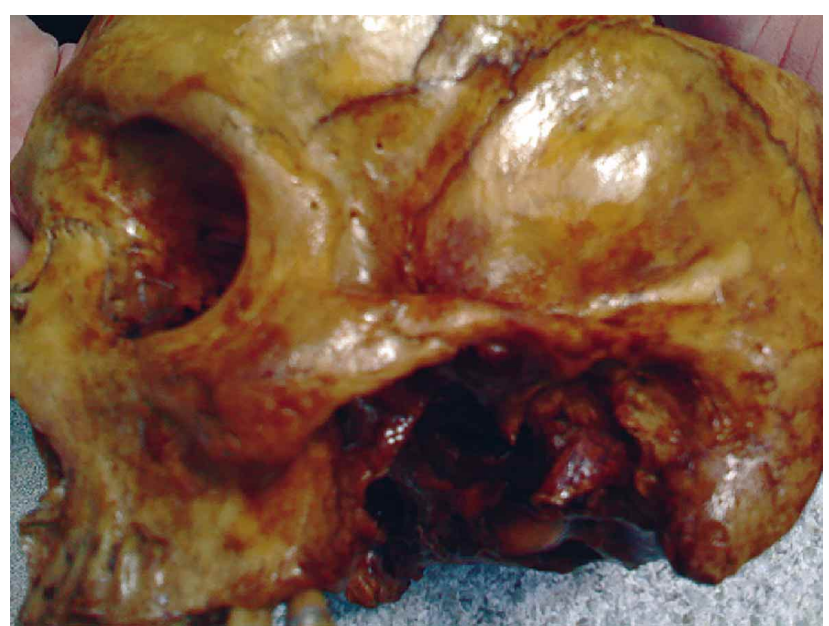

Fig. 1. Se reconocen en este cráneo, en norma lateral y hacia la región postero-inferior, una saliente desarrollada pos-natalmente por tracciones generadas por el músculo esternocleidomastoideo: el proceso mastoideo.

debe ser la base para la creación de listados equivalentes de dichos términos en otros idiomas (Moore \& Dalley, 2002; Chatain \& Delgado, 1989). En consecuencia, la terminología internacional se ciñe solamente a las raíces latinas (López Piñero \& Terrada Ferrandis; Dauber, 2007), con eliminación de las raíces griegas (Chatain \& Delgado); sin embargo, esto no es estrictamente cierto, pues al examinar la actual Terminología Anatómica Internacional se encuentran varios términos de origen griego ampliamente utilizados, como sucede con el término meniscos (Terminologia Anatómica Internacional) que refiere a estructuras intra-articulares de la rodilla (Moore \& Dalley). También se incluye el término apófisis (que se analizará en breve); aún más, el término Anatomía es de origen griego, que proviene de ?natom?, constituida por el sufijo tom? que significa cortar (Boetnner, 1942) y el prefijo ?na que significa a lo largo de (Boetnner), asimilada contemporáneamente por la palabra disección. Por tanto, el término anatomía, que se utiliza desde el tiempo de Hipócrates (460-370 a.C), indica cortar a través de, lo que también da a entender disecar sistemáticamente (Boetnner). Por desgracia, el uso del lenguaje anatómico ha sido parcial (Williams et al., 1998), ya que existe una variedad de términos ambiguos que hacen arduo y confuso el entendimiento de la Anatomía; además, incorporar en el lenguaje técnico la Terminologia Anatómica Internacional lleva a tropiezos y confusiones en la comunicación con colegas de otras latitudes, incluso con aquellos de un mismo país (Tamayo Orrego \& Duque Parra, 2007) que proceden de diferentes escuelas, algunas de ellas basadas en la obsoleta terminología que utilizan sus profesores, sin cuestionamientos lógicos y/o por desconocimiento de la Terminologia Anatomica Internacional, es decir por desactualización. Según los lingüistas, los términos cientí- ficos se diferencian de los vocablos del lenguaje común por su precisión, es decir, por tener claramente delimitados sus significados (López Piñero \& Terrada Ferrandis). Sin embargo, para el caso del término "apófisis" creemos que, basados en descripciones de dicho término, aun hay desconocimiento de su precisión, por eso muchos continúan usándolo a cambio del término "proceso".

\section{DISCUSIÓN}

¿Es válido el término "apófisis" para la terminología anatómica actual? Para corroborarlo o negarlo es necesario tener en cuenta las siguientes dos consideraciones: 1) si la intención es suprimir de la terminología anatómica aquellos términos diferentes al latín; y 2) si el término es suficientemente claro y preciso. Con relación a la primera consideración, el término apófisis debería eliminarse de la terminología por no ser de origen latino, pues dicho término deriva del griego apóphysis (Chatain \& Delgado; Diccionario terminológico de ciencias médicas; Moliner, 1991), el cual se compone de la partícula apó que significa fuera de (Boetner), separación (Cadavid Restrepo, 1942), y physis que significa crecimiento (Boetner; Kardong \& Salido, 1999), excrecencia (Cadavid Restrepo; Chatain \& Delgado; Real Academia Española, 1992), brote (Cadavid Restrepo), alejado de algo (Lippert, 2005) o proyección (Stedman).

En cuanto a la segunda consideración, el término apófisis es asimilado por algunos como lo que crece afuera de (Boetner), mientras que para otros se refiere a una prominencia destinada a una inserción muscular (Lippert, 2005); para otros tantos el término se refiere a una tumoración que deforma la superficie cutánea de los animales (Diccionario enciclopédico ilustrado Norma, 1996); otros más consideran que son salientes voluminosas a manera de una prolongación del hueso donde se encuentran, mientras que las protuberancias son salientes menos voluminosas que las apófisis (Santacoloma Garrido, 1943). Algunos más definen apófisis como un sobrecrecimiento óseo que carece de un centro independiente de osificación (Stedman, 1990). Pero también se le define como una eminencia natural de un hueso que se continúa con éste (Chatain \& Delgado). Además, las salientes pequeñas (y no se clarifica de qué dimensiones) no cuadran en este término, pues descartaría por ejemplo las salientes palatinas, en comparación a la basilar del occipital $\mathrm{y}$ con las mastoides o las estiloideas. Como se nota, no hay claridad en la definición, por lo que el término apófisis se hace confuso.

En la lengua castellana, el término apófisis se asimila con el significado de saliente, prominencia (Real Acade- 
mia Española), que sirve para su articulación o para las inserciones musculares. Otras interpretaciones indican que la apófisis normalmente forma parte de una articulación (Lexis, 1979), pero estas anotaciones complementarias no parecen ser muy precisas, pues las mastoides, las pterigoides, las coracoides, las hioideas y muchas otras más no forman parte de articulaciones. De nuevo, se nota la falta de claridad en el término. En el lenguaje especializado de la Anatomía, las eminencias que presentan algunos huesos, cualquiera sea su forma, son apófisis, término que sin duda resistirá todas las tentativas que puedan hacerse para substituirlo por denominaciones más precisas y científicas (Testut \& Latarjet, 1951). No obstante, las eminencias óseas se dividían antiguamente, entre otras, en apófisis o eminencias que nacen del mismo cuerpo del hueso del que parecen ser prolongaciones (Cruveihier, 1854), y las prominencias óseas se organizaban en orden decreciente de tamaño en apófisis, trocánteres, tuberosidades, tubérculos y espinas (O’Rahilly, 1989), lo que ha contribuido más a la confusión. Según lo anterior, parece entonces que un trocánter y una espina, aunque sobresalen del hueso, no son apófisis. Extrañamente el término apófisis aparece en la actual Terminologia Anatomica Internacional como término general del sistema esquelético, referenciado con la identificación A02.0.00.023 (Federative Committee on Anatomical Terminology, 1998), pero al revisar dicho texto no se encuentra explicito el término para ninguna saliente del cuerpo humano. Entonces, ¿qué certeza o precisión existe al denominar a una saliente ósea como apófisis? Esto deberá aclararse o al menos llegar a un consenso en su definición, pues el propósito es depurar la terminología anatómica de términos confusos con el fin de utilizar un lenguaje más preciso para la comunicación. ¿Será acaso que en la Morfología nos estamos restringiendo a límites estrictos que imponen los diccionarios académicos a expensas, en muchos casos, de la precisión que requiere el lenguaje especializado? ¿No vale acaso la pena insistir por un lenguaje morfológico coherente y claro? (Navarro, 2008). El término complementario para apófisis es el de proceso, que significa prolongación (Diccionario Terminológico de Ciencias Médicas), el cual se deriva del latín processus (Stedman, 1990; Federative Committee on Anatomical Terminology), que se asimila por prominencia, proyección (Dorland, 2009), eminencia, protuberancia o parte proyectante de un hueso (Webster, 1949). Como se puede ver, el término es más preciso para definir lo que se quiere resaltar de un hueso, además aparece con el referente A02.0.00.028 en la Terminologia Anatómica Internacional y es utilizado para referirse a las múltiples salientes óseas, como lo son, entre otros: el proceso coronoideo mandíbular, el estiloideo radial, el estiloideo ulnar, el palatino, el cigomático, el pterigoideo, el mastoideo, el estiloideo del hueso temporal (Federative Committee on Anatomical Terminology).

\section{CONCLUSIÓN}

En concordancia con la actual Terminología Anatómica Internacional del Comité Federativo de Terminología Anatómica (FICAT), el término vigente que se utiliza para designar las prolongaciones de los huesos es el de proceso en lugar de apófisis. Puesto que los términos apófisis y proceso existen en la Terminología Anatomica Internacional, se propone eliminar el término apófisis de dicho texto por ser poco preciso, además por ser de origen griego.

DUQUE, P. J. E. \& BARCO, R. J. ¿Apophyses or process? a logical contribution to the construction of anatomical terminology. Int. J. Morphol., 32(4):1190-1193, 2014.

SUMMARY: In this study we sought to question the inclusion in the International Anatomical Terminology two terms with different origins to designate a single structure. Under the provisions of the Federation of Associations of Anatomists (IFFA) a list of Latin anatomical terms was established, in order to facilitate scientific communication, but in this list are some words of Greek origin that contradict the initial precept. The term apophysis is of Greek origin, and its meaning is ambiguous and imprecise, it lends itself to different interpretations, sometimes erroneous, when applied to designate some bony protrusions. In contrast, the term process, which originates from the Latin processus, provides a more precise meaning less confusing and which can be applied to designate all bony protrusions. Since the unexpired term in the current International Anatomical Terminology is the process to designate bony extensions, thus aiming to eliminate such terminology apophysis, being less precise and of Greek origin.

KEY WORDS: Apophyses; Anatomy; Osteology; Process; Terminology.

\section{REFERENCIAS BIBLIOGRÁFICAS}

Boettner, J. M. Etimología griega y latina para el uso médico. Buenos Aires, El Ateneo, 1942.
Cadavid Restrepo, T. Raíces griegas y latinas. Etimologías médicas y biológicas. Medellín, Ministerio de Educación Nacional de Colombia, 1942. 
Chatain, L. I. \& Delgado, G. A. Anatomia humana. Cali, Universidad del Valle, 1989.

Cruveilhier, J. Tratado de anatomía descriptiva. Madrid, Imprenta de la Sociedad tipográfico-editorial, 1854.

Dauber, W. Pocket Atlas of Human Anatomy. New York, Thieme, 2007.

Diccionario enciclopédico ilustrado Norma. Barcelona, Norma S.A., 1996.

Diccionario Terminológico de Ciencias Médicas. Barcelona, Salvat Editores S. A., 1983. pp.815.

Dorland, W. A. Dorland's Pocket Medical Dictionary. Philadelphia, Elsevier Saunders, 2009.

Duque Parra, J. E.; Gómez Arias, N. C,; Giraldo Ríos, D. P. Nomenclatura anatómica internacional: un horno microondas en el interior de un volcán activo? Medicina UPB, 21(1):43-55. 2002.

Duque-Parra, J. E.; Llano-Idárraga, J. O. \& Duque-Parra, C. A. Reflections on eponyms in neuroscience terminology. Anat. Rec. B New Anat., 289(6):219-24, 2006.

Federative Committee on Anatomical Terminology (FCAT). Terminología Anatómica: International Anatomical Terminology. Stuttgart, Thieme, 1998.

Kardong, K. V. \& Salido, J. B. Vertebrados: anatomía comparada, función, evolución. Madrid, McGraw-Hill Interamericana, 1999. pp.84-685.

Lexis. 22. Medicina y salud. Diccionario Enciclopédico Vox. Barcelona, Ediciones Círculo de Lectores, 1979.

Lippert, H. Anatomía con orientación clínica. Madrid, Marban, 2005.

López Piñero, J. M. \& Terrada Ferrandis, M. L. Introducción a la terminología médica. Barcelona, Salvat, 1990. pp.1,75.

Losardo, R. J.; Cruz Gutiérrez, R; Rodríguez Torres, A.; Prates, J. C. \& Valverde Barbato de Prates, N. E. Iberia-Latin-American Symposia of Morphological Terminology (SILAT). First Two Years and Statute. Int. J. Morphol., 28(4):1323-6, 2010.

Moliner, M. Diccionario de uso del español. Madrid, Gredos, 1991. pp.216.

Moore, K. L. \& Dalley, A. F. Anatomía con orientación clínica. Madrid, Medica Panamericana, 2002. pp.633.

Navarro, F. A. Imaginología: ¿hay vida para los términos fuera de la RAE? Rev. Neurol., 46(2):127-8, 2008.
O’Rahilly, R. Anatomía de Gardner. México D. F., Interamericana McGraw Hill, 1989. pp.12.

Real Academia Española (RAE). Diccionario histórico de la lengua española. Madrid, Real Academia Española, 1992. pp.119.

Rich Harris, J. El mito de la educación. Barcelona, Grijalbo, 1999. pp.318.

Santacoloma Garrido, N. Anatomía Humana. Osteología. Bogotá, Librería Voluntad S.A., 1943. p.17.

Stedman, T. L. Illustrated Stedman's Medical dictionary. Baltimore, Williams \& Wilkins, 1990.

Tamayo Orrego, L. \& Duque Parra, J. E. ¿Nódulos axonales? Réplica. Rev. Neurol., 45(3):191-2, 2007.

Testut, L. \& Latarjet, A. Tratado de Anatomía Humana. Barcelona, Salvat. 1951.

Webster, N. Webster's New Twentieth century dictionary of the english language unabridged. New York, The Publishers guild, 1949.

Williams, P. L. \& Bannister, L. H. Anatomía de Gray: bases anatómicas de la medicina y la cirugía. Madrid, Harcourt Brace, 1998. pp.13.

\section{Dirección para Correspondencia: \\ Jorge Eduardo Duque Parra \\ Programa de Medicina \\ Universidad de Caldas \\ Manizales. \\ COLOMBIA}

Email: jorge.duque_p@ucaldas.edu.co

Recibido: 13-02-2014

Aceptado:27-09-2014 